\title{
SMEs need formative infrastructure for business transformation
}

\author{
Klas Gäre and Ulf Melin \\ Linköping University Post Print
}

\section{Tweet}

N.B.: When citing this work, cite the original article.

Original Publication:

Klas Gäre and Ulf Melin, SMEs need formative infrastructure for business transformation, 2011, Journal of Enterprise Information Management, (24), 6, 520-533.

http://dx.doi.org/10.1108/17410391111166558

Copyright: Emerald

http://www.emeraldinsight.com/

Postprint available at: Linköping University Electronic Press

http://urn.kb.se/resolve?urn=urn:nbn:se:liu:diva-71748 


\title{
SMEs NEED FORMATIVE INFRASTRUCTURE FOR BUSINESS
}

\section{TRANSFORMATION ${ }^{1}$}

\author{
Abstract
}

Purpose - ICT has considerable importance for increasing productivity and growth. Using ICT requires resources to create value. As resources are more limited in smaller enterprises, and the contexts and conditions for using ICT in SMEs are not well known, the purpose is to investigate conditions, in the context of sensemaking for ICT adoption and use among SMEs. Method - This study uses a qualitative and explorative methodological point of departure and approach. More than 60 interviews are performed within a geographical region. Empirical data was analyzed for similarities and patterns into themes and topics.

Findings - The article was able to highlight the conditions for using ICT in SMEs by applying a qualitative research approach. The important findings from this research as a formative ICT infrastructure can be viewed as constituted by needs identified among SMEs, in (1) sensemaking, (2) sensegiving, and (3) service infrastructures. In SMEs in general there are less infrastructure and fewer overhead and support services than in larger enterprises. The adoption processes in SMEs differ from the ones in larger enterprises in that they rely more on external relations in a public infrastructure for sensemaking in ICT adoption and use. Research implications - Formative ICT infrastructure in SMEs is not a well-known concept. The need for formative infrastructure in ICT adoption and use in SMEs rely on external partners and other actors in the sensemaking and sensegiving processes. Further research is

\footnotetext{
${ }^{1}$ An earlier and shorter version of this article was published as a conference paper: Gäre, K., Åbom, C., Melin, U. (2008): Formative Infrastructure for ICT-adoption in SME's - A Case Study of Conditions for Progress, in: Golden, W., Acton, T., Conboy, K., van der Heijden, H., Tuunainen, V.K. (Eds.): Proceedings of the $16^{\text {th }}$ European Conference on Information Systems, pp. 1082-1093.
} 
needed for understanding actors and roles better, as well as arenas for sensemaking ICT in SMEs.

Practical implications - Designing the infrastructure for ICT use and development, particularly in SMEs, but also in other enterprises and organizations, requires better understanding of the conditions. The emphasis on infrastructure for ICT adoption processes will help SMEs to receive more relevant investments.

Originality - The study integrates micro- and macro-perspectives and combines theories from different fields to extend the knowledge of formative infrastructure for SME's adoption and use of ICT in terms of firm size and dependency on public infrastructure.

Keywords: Adoption, formative infrastructure, sensegiving, sensemaking, ICT use, SME Manuscript category: research paper 


\section{INTRODUCTION}

This article presents a study of conditions for exploiting information and communication technology $\left(\mathrm{ICT}^{2}\right)$ in small and medium-sized enterprises ${ }^{3}$ (SMEs) in a region in Sweden. Previous studies show that the use of ICT is of considerable importance to productivity and growth of a firm as well as at a national level (Rajaguru and Matanda 2009, Hagén and Zeed 2005, Brynjolfsson and Hitt 2003). However, ICT use requires considerable resources as well as social interaction (Gal, Yoo and Boland 2005, Star 2002, Hanseth and Monteiro 1998) in order to create value. ICT use varies among enterprises to a large extent depending on size and ICT competence, where smaller enterprises have more limited resources in this respect (Persson 2000, Nutek 2004, Tan et al. 2010). The focus and purpose of this study is to investigate the conditions, in the context of sensemaking for ICT adoption and use among SMEs. ICT adoption and use is where the individual makes sense of ICT in relation to the work process, as in sensemaking (Weick 1995, Weick, Sutcliffe and Obstfeld 2005, Tan et al 2010). Sensemaking is the process where people give meaning to experience, and a major premise of social cognitive research is that people act on the basis of their interpretations of the world, and in so doing, enact particular social realities and endow them with meaning (Berger and Luckmann 1967, Weick 1995). This interpretation also applies to ICT when brought into working life, and the notion of technological frames refers to interpretative flexibility, that artefacts (e.g. ICT) may be interpreted in different ways among different social groups, whether they “work” or "don’t work”, depending on who uses them and for what (Bijker 1995). Business functions (e.g. supply chains) are mediated in the relationships of business partners and actors, and in inter organizational IS (IOIS) (Rajaguru and Matanda 2009). Business partners related in relevant social groups interpret and understand the artefact

\footnotetext{
${ }^{2}$ ICT, as defined by the Information Technology Association of America (ITAA) is: "the study, design, development, implementation, support or management of computer-based information systems, particularly software applications and computer hardware."

${ }^{3}$ SMEs according to the current EU definition are companies with fewer than 250 employees.
} 
according to their purposes and apply their understanding (Bijker 1995, Orlikowski 2000, Orlikowski and Gash 1994). The dynamics of sensemaking is not well known in the context of ICT adoption and use in SMEs.

In the reviewed literature the dominant perspective is on implementation of ICT and not on the perspective of the users'- neither individual nor organizational - demands or needs as conditions for sensemaking ICT use. The key question in this article is: What is important in the context of sensemaking ICT in adoption and use in SMEs?

This article is useful for reading and reflection among researchers but also among investigators in municipal services as design conditions in planning. The article is organized with the next section introducing previous studies and theory. The following section (three) is a brief description of the research approach, which is followed by a description of empirical findings and first level analysis (section four). Section five contains conclusions and implications.

\section{INFRASTRUCTURE FOR ICT ADOPTION AND USE}

Looking back, there has been a focus on large organizations when studying the use of ICT (e.g. Weill and Broadbent 1998, Ciborra et al. 2000) but not on SMEs. Previous studies show that enterprise size and ICT competence are important in the exploitation of ICT infrastructure, e.g. e-services and municipality broadband (Nutek 2004). In SMEs, there is a strong connection between ICT use and how much cooperation there is with other enterprises and external actors in general. Users that are accustomed to new technology quickly see many applications and management in SMEs often developing external relations to deploy different kinds of technology knowledge and competence, but also to legitimize technology change and mobilize motivation to renewal. External relations concern foremost customers and suppliers, where demanding customers are known to have an impact on product and technology development, e.g. in the case of EDI (electronic data interchange), a standard of exchanging 
messages more or less imposed on suppliers and subcontractors by large and influential customers. Also relations with colleagues in the same business, local networks of knowledge and consultants are important. Realizing options and possibilities in technology often arise in conversations with colleagues and experts. Common parts of ICT infrastructure are traditionally described in different contexts - public, industry, corporate, local (Weill et al. 1998, Ciborra et al. 2000, Hanseth and Lyytinen 2004). In larger firms there is a relation between available infrastructure and the use of information technology (Beckett 2008). Adoption does not take place as a single decision, but rather as sensemaking processes (Seligman 2006). In these processes, perceptions of the technology change, until apparent adoption or rejection actions are performed. To cope with new information and uncertainties, humans develop a "vision” or understanding of how the environment works (sensemaking). And as we see that ICT has a significant positive influence on processes for creating knowledge (Lopez-Nicolas 2010), we also see that humans communicate this knowledge with others (e.g. partners, employees, investors, potential customers, and suppliers) and gain their support (Weick et al. 2005, Gioia and Chittipeddi 1991). This process: “[...] involves calling into question an obsolete interpretive scheme, framing a new interpretive scheme in understandable and evocative terms, providing guidance for action toward the incipient change and exerting influence to accomplish it" (Gioia and Chittipeddi 1991 p. 446). When organizations are in need of new interpretation patterns, influential actors may attempt to articulate or advocate their vision or preferred interpretive scheme, thus engaging in sensegiving processes and influencing the sensemaking processes of internal and external stakeholders. Sensegiving processes can take place between top and middle managers and between managers and employees. Sensegiving is different from sensemaking, in that the person trying to give sense is attempting to influence other people to perceive and interpret certain actions and events in particular ways. Sensemaking has to do with meaning 
construction and reconstruction by the involved parties as they attempt to develop a meaningful framework for understanding the nature of e.g. an intended strategic change. Sensegiving is concerned with the process of attempting to influence the sensemaking and meaning construction of others towards a preferred definition of organizational reality (Gioia Chittipeddi 1991, Söderberg 2003). Although you cannot force adoption onto reluctant users, there is a force in changing e.g. administrative architecture and slowly the culture changes to adapt to that architecture (Wagner et al. 2006). The dynamics of sensemaking and sensegiving is not well known in the context of ICT adoption and use in SMEs.

From the perspective of the individual, ICT use is about figuring out how new ICT can be integrated in organizational processes, getting the new ICT into the users' understanding. From the organization perspective, ICT use is about the social context for ICT use, the cultural and social context for sensemaking ICT use, in business processes. Communication and socializing relate to the social impact of and on ICT use.

One aspect of sensemaking is about how people, over time, influence their work environment, and then are influenced by it, as the environment is a source of stimuli. The environment has an impact on the users' attitudes towards ICT use where the knowledge of the experience of others is one part, and sensemaking is to incorporate them in one direction or another (adoption or rejection). A formative context (Ciborra and Lanzara 1994) refers to the cognitive frames and institutional and technological arrangements in e.g. an organization. In contexts where limited learning and invention occur, the organization is incapable of enquiring into the existing formative context (Henfridsson 2000).

One assumption from this is that for ICT to be meaningful and sensible in business processes, it takes learning and invention which occur in alignment of ICT adoption, norms and experiences of the organization. 
An example of sensemaking and sensegiving processes is the implementation of an ERP, or a new module of an ERP, or a new version of an ERP. The initial decision is taken by management and motivated by different arguments e.g. in terms of improvements in quality and efficiency, and thereby giving sense to the decision taken. Earlier in this process managers have made sense of the decision to take, of its potentials, risks and expectations on impacts The new technology meets the users in e.g. information and education programs, and finally in the routine use in daily operations. The user makes sense of the new technology in assimilating it into their daily routines. Similar situations occur e.g. in the context of eCommerce, when firms' (e.g. in the role of suppliers and buyers) meet and present experiences of its use, giving sense to the investments made, and listeners make sense of the message in translating it into their own firms and how it could work there. So what is not well known is how social contexts influence sensemaking in ICT adoption, and what constrains or supports ICT adoption in SME’s.

\section{RESEARCH APPROACH}

The methodological point of departure and approach in this study is qualitative in line with the explorative aim. The work performed corresponds to central concepts and ideals in interpretive and qualitative research, such as interpretation and pre-understanding (cf. Walsham 1995; 2006). The research is designed for finding indications and allow for elaboration on the subject of sensemaking and sensegiving processes in ICT adoption among SME's. The design is chosen to allow for relevance and realistic responses and understanding in exploring and describing the subject. In our study we rely heavily on qualitative interviews as a source to generate empirical data. The research questions are grounded in a sociotechnical perspective aiming towards understanding and interpreting the complexity and intertwined nature of ICT adoption and use. The theories about sensemaking, sensegiving, and social infrastructure have been a guide in sensitizing concepts and interpreting processes 
(Klein and Myers 1999) in choosing the scope of the study, and in designing themes in data collection, and also in the analysis of collected data. In addition to interviews, data were collected from documents such as marketing documents, policy documents, project reports, data stored in databases, and web pages - to get a more varied and truthful view as empirical data triangulation (Denzin and Lincoln 1994).

\section{Data collection}

Data were collected using qualitative semi-structured interviews (cf. Patton 1980) and reviewing documents such as marketing documents, policy documents, project reports, data stored in databases, and web pages etc. Primary and secondary data enable us to triangulate empirical data (as discussed above) the results and /or interpretations of the findings from the interviews.

Documents such as protocols, press messages, newspaper articles, company pamphlets, were analyzed to provide a better understanding of events in Tranås municipality and the business situation of the firms. Situations that can be interpreted differently based on the position and the insight related to a certain phenomenon that an interviewee has compared with e.g. a project description.

\section{Interviews}

The (face-to-face) interviews and other supplementary material were collected in the period of 2000 until 2008, with 9 enterprises during 2000 and 2001, 24 interviews that were carried out during late autumn of 2003 and winter of 2004, with municipal politicians (2), municipal managers (2), municipal officials and project leaders (4), managers in large and small enterprises in both industry and trade (10), and also representatives from professional and industrial organisations (3). During the interviews the respondents were asked to tell their story; how they perceived the process in hindsight; what events they regarded as critical; the general ICT situation in Tranås (a regional area in the southern part of Sweden; further 
described below); implications of the TRAMAN (TRAnås Metropolitan Network) implementation and future intentions in relation to TRAMAN and in general. During 2005 interviews were carried out with municipality ICT officials (4), general meetings with enterprises in Tranås for presentation and discussion of results (2). Group interviews were also carried out during 2005 with people from different lines of business as trade, industry, and service, in all, 21 people from 21 companies with fewer than 50 employees. These interviews were performed in order to gather data from smaller companies. Finally, five managers from three firms were interviewed in 2006 in order to capture even managers’ opinions and thus get a more complete picture of the visions, needs and pre-requisites that different representatives have regarding the research question indicated in our aim. During 2007 - 2009 interviews and observations were made with the board of the organization working with development of and for firms and the municipality of Tranås. The interviews concerned questions on how the TRAMAN were understood and its importance for changing the way of doing business, the importance of communication and interaction for the firms, and what enhances this interchange (i.e. strategies or issues of importance). We also asked how the information infrastructure should be developed to support interchange of knowledge, information and other issues of importance for the region to stimulate communication and interaction between different actors in order to stimulate the region. This article belongs to a series of articles developed in this project and presents only the data related to the aim of this study. There are other studies in which questions and issues omitted in this article are presented i.e. how the information infrastructure should be developed to support business activities, how to stimulate grow or which strategies have to be adopted. 
All interviews were recorded and some also videoed. The length of the interviews was between 1.5 to 2.5 hours. The content of all the interview transcripts was also read in order to identify issues and topics as they were framed by organizational members.

\section{Data analysis}

We looked for similarities and patterns in the interviews, using tables and organizing texts in a recursive way, where datasets were summarized, those summaries then further summarized, and so on. In the summarizing activity ideas were checked with secondary data. Questions and answers were put into large matrices for finding topics and themes in both a textual and a more graphic way. These themes and topics then were analyzed and aggregated in order to arrive at a set of themes that were common or recurring. Then data were reviewed in an iterative process of interpretations and reflections as described in above in the introduction to this section.

\section{Credibility of results}

The long period of data collection and the recursive analysis of data - also involving feedback from interviewees - together with the relatively large amount of interviews with people from a broad array of ICT use, contribute to making the results trustworthy.

\section{INFRASTRUCTURE NEEDS AMONG SMES}

The case is SMEs in the municipality of Tranås, Sweden, and its 18000 inhabitants (http://www.tranas.se/).Until the end of the 1980s the fur industry was a very important business sector in Tranås with around 2500 employees. For various reasons this industry collapsed in the late 1980s, causing many problems at the municipality level such as unemployment, diminishing population, less taxes paid etc. The situation called for action in order to facilitate growth. One of the early actions in Tranås was to invest in regional development including an all-fibre network (broadband) in order to connect enterprises, people, associations, and the public sector in the TRAMAN project. There are 1752 
registered enterprises in Tranås, most of them small: 1137 have 1 employee, 585 enterprises have 2 to 50 employees. The majority has no ICT competence of their own; they rely on suppliers for services and support in order to serve their customers in turn.

\subsection{The need for infrastructure}

In the interviews, the Internet is regarded as more of an option than a threat. It serves as a complement for active customers who are using the Internet to inform themselves about the product, e.g. characteristics, price level etc, but still need the physical visit for guidance. Many products are complex and sales personnel and customers have a great need for information. When the net shops compete with the price however, the net can become a threat. The enterprises in Tranås must meet this with knowledge, competence, and service around the products they offer. Competence is an important condition for success in the competition, as well as ability to deal with competences needs. It is important for their customers, which often are SMEs, to have a reliable service organization to turn to in the event of problems in order to avoid standstill. There is a need, especially among smaller enterprises, for local suppliers for service and support which is an important role for smaller suppliers. Service and support concern technical matters as well as applications and integration in work processes which develop the enterprise. This need is not covered by net operating suppliers. These services play an important role in the customers' investments in ICT and that they work and can be used in the further development of the enterprise. In cases of service and support, suppliers often make problem analyses and measurements via the Internet or by telephone calls and also most software problems are adjusted via the Internet together with telephone support. Hardware problems have to be attended to on site. In turn suppliers (e.g. Hewlett Packard and Microsoft) have support service for the local support suppliers who have direct contact with the customer/end user. This is done almost exclusively via the Internet. To be able to perform a service efficiently, access to the Internet is demanded 
independently, whether you operate from home/office or on the customer site i.e. service needs.

We realized that the need for infrastructure in the ICT area, are different among small (fewer than 10 employees) and slightly larger enterprises (10 - 50 employees) regarding resources to maintain and develop an ICT infrastructure. The smaller enterprises have no corporate infrastructure of their own, whereas the larger enterprises have more, yet still need infrastructure. The smaller enterprises have to rely on external partners and suppliers, corresponding to a need for cooperation. From the interviews we see other important needs for cooperation emerging, besides technology, e.g. business models into which ICT is to be integrated. Business models may come from ideas given by persons in a corporate structure or business partners or colleagues. They come in many shapes as e.g. business objects, best practice, ERP systems, business sector practices i.e. cooperation needs.

In sum we see three areas of needs:

- Competence needs

- $\quad$ Service needs

- Cooperation needs

\subsection{Strategies for coping with need for infrastructure}

Enterprises cope with needs and plans, and three strategies emerge in the present empirical data: competence strategies, cooperation strategies, and service strategies.

\section{Competence strategies}

Access to competence can occur in several ways - e.g. consultants, financers, and also via partners and suppliers. An important source for competence is investing in training employees in the enterprise with rather large sums, e.g. 10 to 15 days a year per technician, which equals to about one month working time and billing. All the interviewees point out critical conditions for growth such as access to competence, developing own competence, information about 
important news, being in the current news, keeping track of what is going on. Earlier findings show that all enterprises need a basic level of ICT infrastructure capability to implement new ideas and systems (Lopez-Nicolas 2010, Broadbent and Weill 1997).

Regarding ICT, the interviews point in the direction of more focus on net learning instead of courses, video conference system instead of telephone meetings and travelling. When an enterprise reaches a certain size, it requires more system support. All companies interviewed mentioned their need for support in business intelligence, firstly to have access to important information in the ICT systems, and secondly to have the ability to interpret the data and perform analyses which can be followed over time. Competence strategies are about means for interpretation and sensemaking news as options for business development with ICT.

\section{Service strategies}

Services and support are central to the growth of the interviewed enterprises - to grow as a product. "Our chance is to have a working service and support organization to the products we sell”. Service is identified as an important tool in the competition, and this is where our 'cause for life' lies. Compared with the change in shopping patterns where the customer gets informed via the Internet (web services) before making, the final decision is taken by the customer in the shop, the Internet together with the competence of the sales person is the service in shopping, so to speak. This applies to all interviewed enterprises, in more or less direct ways. In this regard the service part of sales work or the product's value increases e.g. you cannot sell a heating pump without a rather substantial chain of information. All enterprises interviewed invest in this, in different ways. Services are about support in use and business development with ICT.

\section{Cooperation strategies}

Most enterprises develop different kinds of cooperative strategies to cope with growth and development. One example is to cooperate with colleagues or similar suppliers within a 
geographical area. Another is to merge with a larger cooperation, and still another is to cooperate with suppliers and customers in a "symbiotic" way, more like a social network where enterprises help each other in many ways - e.g. ideas, technology, competence, employees, and capital. Cooperation with retailers is important and will increase in importance. In this situation the web is both a threat and an option. Almost all communication with suppliers is via the Internet and communication with customers is via the Internet as well as direct personal contact (but there are differences among the enterprises interviewed). A transfer of responsibilities is observed by the interviewees (retailers) in contacts with suppliers. The customer is actively responsible for making contacts and inquiries. The main supplier rarely visits the customer any more (sub supplier or retailer). Personal contacts are established at fairs and exhibitions. The new communication patterns concerning information, services, and competence - via the web are completed with local meetings where those interested take part. The active part is the information seeking sub-supplier with a reallocation of responsibilities concerned with seeking information and the costs for this (e.g. travel costs). This re-allocation is enhanced by web-services, where earlier visits from sales representatives are substituted by web-services. Bearing in mind that these services can be open to anyone, as there is no extra cost to offer them to a small sub-supplier in a small market in comparison with a large market, one can say that this development favours small suppliers and small markets, if they only have resources to take part of the service. Communication can occur over large distances without problems. Having access to the services and support of a chain or a franchise is of vital importance, as a kind of infrastructure to exist at all, to expand, grow and develop, to be able to grow and consolidate in cooperation. Another way of putting it is that the option to rely on "a big sister" is crucial. Cooperation strategies are about giving and obtaining ideas and experiencing from the context for use and business development of ICT, relating to sensegiving. 


\section{CONCLUSIONS}

An important contribution in this article is that we have identified three strategies for coping with the need for infrastructure to create business benefits: competence, cooperation, and service. The leading star for enterprises to develop strategies is business value, together with organizational readiness and external pressure (e.g. the present market). The need for infrastructure touches on different contexts such as local, firm-wide and public infrastructure. In the daily operation the two first mentioned contexts are important as facilitators. These two contexts are important as communication may be easier within firms in comparison to communication in a public infrastructure. You can communicate and express desire for change and expect to have an impact, when communicating with a local or firm-wide function more easily than in the same situation concerning a function in e.g. Microsoft's Excel. When analyzing SME's needs for infrastructure, three types emerge as a result in the present study - (1) sensemaking infrastructure, (2) sensegiving infrastructure, and (3) service infrastructure, as cornerstones of a formative ICT-infrastructure:

Sensemaking infrastructure corresponds to need for:

- Competence in many ways - for use of ICT applications, for analyzing the enterprise (or parts of interest), planning and monitoring, for hiring employees with new ideas, accessing expert knowledge from consultants, accessing expert knowledge from suppliers.

- Analysis - somewhere between communication and planning/monitoring is analysis, as e.g. analysis of communicated interest in groups of products, where input comes from communication and output is given to planning and monitoring.

Sensegiving infrastructure corresponds to need for:

- Tools for planning and monitoring - ERP systems, new combinations of business processes and ICT, ideas for extracting large amount of data to intelligible information.

- Occurrence within all three parts of formative infrastructure. 
- Triggers for sensemaking.

Service infrastructure corresponds to need for:

- Service and support - both as a need and as a product to compete with.

- Tools for communication and supporting systems and tools - the Internet, web services, system integration - both with internal systems as well as external ones.

- Larger enterprises found within the firm-wide infrastructure.

- SMEs having access to public service providers.

In our research we have identified that the interaction is about exchanging ideas, experiences, knowledge, and triggering sensemaking by giving input to evolution and business development. The concept of information infrastructure (Hanseth et al. 2004) does not, however, take into account the social conditions concerning the interaction to occur. Nor does it take into account the conditions in the context for ICT use. These conditions can be further understood and elaborated on in more detail and in relation to business needs of SMEs by the three groups of formative infrastructure - sensemaking, sensegiving and service as shown in our research; that adds further knowledge to the literature focusing infrastructure. The notions of technologies-in-practice (Orlikowski 2000) point at conditions for use as interpretive, technological and institutional, and the context for their emergence is that of larger enterprises. In larger enterprises there are rich structures of rules and resources for technology-in-practice as firm-wide infrastructure, but this is not the case in SMEs. SMEs have to rely on public infrastructures for covering their needs. From the SME perspective firm size is an important part of the social context of ICT adoption and use. The latter aspect adds further knowledge concerning the SME situation adopting and using ICT.

We conclude that firm size is crucial in the development of strategy for satisfying the need for infrastructure, where SME's needs for infrastructure are different than those in larger firms in the following respects: 
- SME rely on public infrastructure (Broadbent and Weill 1998) to cover needs for competence, service and cooperation

- SMEs also rely on public infrastructures for sensemaking and sensegiving processes, and a secondary need becomes visible, a need for arenas for encounters in order to facilitate sensemaking and sensegiving.

- From an individual perspective this is about understanding ICT for use in business processes. From an organization perspective this is about the context for sensemaking and sensegiving. From both perspectives SMEs rely on public infrastructures to a large extent.

- A formative context (Ciborra and Lanzara 1994) for SMEs rely to a large extent on cognitive frames, and institutional and technological arrangements outside of the firm.

- The availability of arenas for interaction, both locally and virtually is important in the social context influence and sensemaking in SMEs.

\subsection{What is a formative infrastructure for SMEs in ICT adoption and use?}

We identify a need for extending the concept of formative context (Ciborra and Lanzara 1994), for analyzing ICT adoption and use in SMEs, to make it more useful in relation to firm size. The concept of formative context is not specific in this respect and extending it to formative infrastructure creates the option of analyzing different kinds of formative infrastructures e.g. in terms of local, corporate and public. A formative ICT infrastructure constituted by the needs identified among SMEs in our study contains three parts: (1) sensemaking, (2) sensegiving, and (3) service infrastructures (above). Sensemaking infrastructure (1) is about conditions for making sense of ICT, to be able to realize what ICT can be used for in business development, to make sense of ICT in a business development perspective. Sensegiving infrastructure (2) is about imposing meaning to others about how ICT can be used in business development. Sensegiving is about realizing the business value of 
new IS-functions or existing IS-functions used in new ways, or for that matter, the lack of business value in some IS-functions. Service infrastructure (3) is about having the base work installed as intended and the importance of services and functions in a corporate infrastructure, and also that the lack of it has to be handled by those (SMEs) that do not have access to that kind of services within their own business. So what we see is that formative ICT infrastructure refers to the situation where enterprises deal with ICT when developing their enterprises and ICT areas to invest in. Empirical data of this study indicates that the perceived business value was the most important explanation for decisions, when it comes to investments in ICT.

\subsection{Impact - covering needs for formative infrastructure for SMEs in facilitating ICT use}

ICT is important in coping with needs. However investments in ICT is first of all viewed as a question of comparing benefits with costs, i.e. its business value, in all interviews. This means that all interviewees take a business view of investments in ICT. This could also imply that there is little interest in ICT (“why do we find so little about ICT in the interviews?”) but more in the business or economic benefits of technology, i.e. the beneficial consequences of ICT investments. To continue this line of thought, there is an implication that competence is not about ICT itself, but its business impacts - experience from failure and success. The interviewees perceived a demand for competence to achieve shorter lead times, slim lined, just-in-time, stock, and increased rate of turnover. So competence is an important ingredient of means for interpretation and sensemaking, where cooperation contains ingredients of idea generation and sensegiving, and access to service is important as a product both to delivering and buying.

The users of ICT act and use ICT based on their personal interpretation and understanding. In order for change to occur there is a need for influencing these interpretations and there is a need for interaction in sensemaking and sensegiving. Our findings confirm earlier research in 
technology use (Hanseth and Lyytinen 2004, 2006, Orlikowski 2000) and reveal that technology use is a complex process and also a sensemaking process (Weick 1995). Technology use is a process where users make objects around them rationally accountable to themselves and to reach some order in their everyday working life. In the processes there are several actors influencing both in sensemaking and sensegiving directions. We argue that there are needs among SMEs in these processes and that actors come into the processes in different ways, as business actors, internal actors, or general actors as ICT and the Internet. The SMEs in our study have needs for better working sensegiving-sensemaking processes; they have needs for images and experience of working ICT in different business processes. These processes are important in ICT adoption, and they occur in all kinds of enterprises, but there is a difference in resources for accomplishing these cycles. From this it comes that one important property, when describing SMEs, is size, but also three other properties are important - independence, limited resources and lack of competence. The SMEs studied show examples of these sensemaking-sensegiving cycles, double interacts (Weick 1979), in that they consider it very important to be members and parts of all kinds of networks, e.g. Rotary, industry networks, friends, sporting friends and more.

So returning to the question of what is formative infrastructure for SMEs, from the SME perspective compared to larger enterprises (Beckett 2008), there is less infrastructure and fewer overhead services and that these are to be found outside the SME. Firm-wide infrastructure is smaller in SMEs, and there are more or less only two kinds of infrastructure for SMEs - local and public, and SMEs, to a large extent, are referred to and depend on, public infrastructure. We have identified a number of implications for a formative infrastructure in adopting and integrating ICT with business processes in SMEs. Conditions for the integration are to be found in the formative infrastructure, in terms of knowledge, competence and interpretative frames. ICT adoption involves identity construction, and 
negotiations around sorting relevant meanings from irrelevant to reach a shared understanding. The process of formatting infrastructure and being formatted by it could be expressed as formative infrastructuration, to mark its ongoing character. Into this process comes what is mentioned earlier as knowledge for use of ICT, triggers sensemaking. For SMEs it is in these respects that there is a difference compared to larger enterprises.

The adoption processes in SMEs differ from the ones in larger enterprises. The ICT artefacts are elements in the formative infrastructure that shape the routine behaviour of actors in enterprises. ICT adoption is the process where the formative infrastructure is maintained as well as changed by actors enacting this context. The important aspect here, based on this study, is that this is a process, a formative context that is constantly moving, and is to be viewed as sensemaking-sensegiving processes. This implies that SMEs are different from larger enterprises - SMEs rely more on external relations in a public infrastructure. Larger enterprises more often have these needs covered by its firm-wide infrastructure.

\section{References}

Beckett R. C. (2008). Utilizing and adaptation of the absorptive capacity concept in a virtual enterprise context. International Journal of Production Research, Vol. 46, No. 5, 1 March 2008, 1243-1252

Berger, P. and T. Luckmann (1967). The social construction of reality. Penguin Books.

Bijker, W. (1995). Of Bicycles, Bakelites, and Bulbs. Toward a Theory of Sociotechnical Change. Cambridge, England, MIT Press.

Broadbent, M. and Weill, P. (1997). Management by Maxim: How Business and IT Managers Can Create IT Infrastructures. Sloan Management Review, Spring 1997, 38,2, pg 77 ff.

Brynjolfsson, E. and L. M. Hitt (2003). Computing Productivity: Firm-level Evidence. MIT Sloan School of Management.

Ciborra, C. U. and G. F. Lanzara (1994). Formative contexts and information technology: Understanding the dynamics of innovation in organizations. Accounting, Management and Information Technologies, 4, 61-86. 
Ciborra, C. U., Braa, K., Cordella, A., Dahlbom, B., Failla, A., Hanseth, O., Hepsø, V., Ljungberg, J., Monteiro, E. and K. A. Simon (2000). From Control to Drift: The dynamics of Corporate Information Infrastructures, Oxford University Press.

Denzin, N. K. and Y. S. Lincoln (1994). Entering the Field of Qualitative Research. In N Denzin, N. K. and Lincoln, Y. S. (Eds.) Handbook of Qualitative Research. Sage.

Gal, U., Yoo, Y. and R. Boland (2005). The dynamics of boundary objects, social infrastructures and social identities. In: Bartmann, D., Rajola, F., Kallinikos, J., Avison, D., Winter, R., Ein-Dor, P., Becker. J., Bodendorf, F., Weinhardt, C. (Eds., 2005) Proceedings of the 13th European Conference on Information Systems, Regensburg, Germany, May 26-28, 2005, 804-816.

Gioia, D. and K. Chittipeddi (1991). Sensemaking and Sensegiving in Strategic Change Initiation. Strategic Management Journal, 12, 433-448.

Hagén, H.-O. and J. Zeed (2005). Does ICT-use Matter for Firm Productivity? Yearbook on Productivity 2005, Stockholm, Statistics Sweden.

Hanseth, O. and E. Monteiro (1998). Understanding Information Infrastructure. http://heim.ifi.uio.no/ oleha/Publications/bok.html

Hanseth, O. and K. Lyytinen (2004). Theorizing about the Design of Information Infrastructures: Design Kernel Theories and Principles. Sprouts: Working Papers on Information Environments, Systems and Organizations, 4, 207-241.

Hanseth, O. and M. Aanestad (2003). Design as bootstrapping. On the evolution of ICT Networks. Healthcare, Methods of information in medicine, 42, 385-391.

Henfridsson, O. (2000). Ambiguity in IT adaption: making sense of First Class in a social work setting. Information Systems Journal, 10, 87-104.

Klein, H. K. and M. D. Myers (1999). A set of principles for conducting and evaluating interpretive field studies in Information Systems. MIS Quarterly, 23, 67-94.

Lopez-Nicolas C, Soto-Acosta P. (2010). Analyzing ICT adoption and use effects on knowledge creation: An empirical investigation in SMEs. International Journal of Information Management, article in press journal homepage: www.elsevier.com/locate/ijinfomgt 
Nutek (2004). Hur kan IT-kompetensen öka i små och medelstora företag? [In Swedish] In Nutek (Ed.) Stockholm, Sweden, Nutek (the Swedish Agency for Economic and Regional Growth).

Orlikowski, W. (2000). Using Technology and Constituting Structures: A Practice Lens for Studying Technology in Organizations. Organization Science, 11, 404-428.

Orlikowski, W. and D. C. Gash (1994). Technological Frames: Making Sense of Information Technology in Organizations. ACM Transactions on Information Systems, 12, 174-207.

Persson, J. T. (2000). Kommunikationerna och den regionala utvecklingen. [In Swedish] Regionalpol. utr. 5 ed.

Rajaguru R, Matanda M J, (2009). Influence of inter-organisational integration on business performance. The mediating role of organisational-level supply chain functions. Journal of Enterprise Information Management, Vol. 22 No. 4, pp. 456-467

Seligman, L. (2006). Sensemaking throughout adoption and the innovation-decision process. European Journal of Innovation Management, 9, 108-120.

Söderberg, A.-M. (2003). Sensegiving and sensemaking in an integration processes. In Czarniawska, B. and Gagliardi, P. (Eds.) Narratives we organize by. Philadelphia, PA, USA John Benjamins.

Star, S. L. (2002). Infrastructure and ethnographic practice - Working on the fringes. Scandinavian Journal of Information Systems, 14, 107-122.

Tan K S, Chong S C, Uchenna C E. (2010), Internet-based ICT adoption among SMEs Demographic versus benefits, barriers, and adoption intention, Journal of Enterprise Information Management, Vol. 23 No. 1, pp. 27-55

Wagner, E. L., Scott S. V. and R. D. Galliers (2006). The creation of ‘best practice’ software: Myth, reality and ethics. Information and Organization, 16, 251-275.

Walsham, G. (1995). Interpretive case studies in IS research: nature and method, European Journal of Information Systems, (4), 74-81

Walsham, G. (2006). Doing interpretive research, European Journal of Information Systems, 15(3), 320-330.

Weick, K. E. (1979). The social psychology of organizing. New York, McGraw-Hill.

Weick, K. E. (1995). Sensemaking in organizations. California, Sage Publications Inc. 
Weick, K. E., Sutcliffe, K.M. and D. Obstfeld (2005). Organizing and the process of sensemaking. Organization Science, 16, 409-421.

Weill, P. and M. Broadbent (1998). Leveraging the New Infrastructure: How Market Leaders Capitalize on Information Technology. Boston, Mass., Harvard Business School Press. 